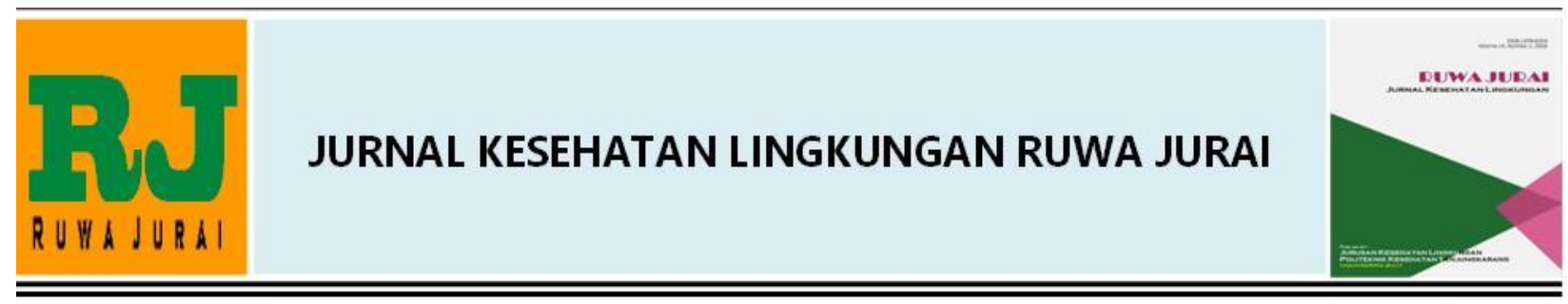

\title{
PENILAIAN RISIKO KERJA MENGGUNAKAN METODE HIRARC DI PT. SINAR LAUT INDAH NATAR LAMPUNG SELATAN
}

\author{
Dwi Desianna $^{1 *}$, Prayudhy Yushananta $^{2}$
}

1,2 Department of Environmental Health, Poltekkes Kemenkes Tanjungkarang.

\section{Artikel Info :}

Received 28 Juli 2020

Accepted 18 Agustus 2020

Available online 24 Agustus 2020

Editor: Ferry Kriswandana

Key word :

HIRARC, Risk assessment, Safety, Risk

Kata Kunci :

Risiko, penilaian risiko, HIRARC, keselamatan kerja.

Ruwa Jurai: Jurnal Kesehatan Lingkungan is licensed under a Creative Commons AttributionNonCommercial 4.0 International License.

\begin{abstract}
A b stract
PT Sinar Laut Indah is a concrete manufacturing plant that has a risk of occupational accidents and occupational diseases due to exposure to particulates, use of work tools, and work methods. The purpose of this research is to find out what are the dangers in a factory, to assess the risk (risk assessment) and risk control (risk control) at each work stage using the HIRARC method. The work risk assessment uses the HIRARC method, which consists of three stages of assessment, namely hazard identification, risk assessment and risk control. The research subjects were all activities in the paving block production section including tools, materials and work processes. Data collection was carried out by observing and measuring exposure, which was then standardized using two risk assessment parameters, namely probability/likelihood of hazard and severity of the hazard. Risk control is the final stage formulated based on the results of the risk assessment from the previous stage. The results of the study found 4 activities in the high category, mixing and stirring of materials, checking rolling boxes, paving blocks presseing, and cleaning the remaining material. The highest risk of occupational diseases is respiratory problems and skin or eye irritation during the mixing and stirring activities of the ingredients, as well as cleaning the remaining materials. Meanwhile, the highest risk of work-related accidents is in rolling box-checking activities. The use of the HIRARC method and the application of probability/likelihood of hazard and severity of hazard are good enough to assess the risk of occupational accidents and occupational diseases. Carrying out repair and maintenance of machines, determining danger zones, using personal protective equipment, and administrative controls are efforts that must be made to avoid risks due to work.
\end{abstract}

PT Sinar Laut Indah merupakan pabrik pembuatan beton yang memiliki risiko kecelakaan kerja dan penyakit akibat kerja akibat paparan partikulat, penggunaan alat kerja, serta cara kerja. Tujuan penelitian ini adalah untuk mengetahui apa saja bahaya yang ada di suatu pabrik, menilai risiko (risk assessment) dan pengendalian risiko (risk control) pada setiap tahapan kerja menggunakan metode HIRARC. Penilaian risiko kerja menggunakan metode HIRARC, yang terdiri dari tiga tahap penilaian yaitu identifikasi hazard, penilaian risiko, dan pengendalian risiko. Subjek penelitian adalah seluruh kegiatan pada bagian produksi paving block meliputi alat, bahan dan proses kerja. Pengumpulan data dilakukan dengan observasi dan pengukuran paparan, yang selanjutnya distandarisasi menggunakan dua parameter penilaian risiko yaitu probability/likelihood of hazard dan severity of hazard. Pengendalian risiko merupakan tahap akhir yang dirumuskan berdasarkan hasil penilaian risiko dari tahap sebelumnya. Hasil penelitian mendapatkan 4 kegiatan dengan kategori tinggi, yaitu pencampuran dan pengadukan bahan, pengecekan rolling box, pencetakan paving block, dan pembersihan sisa material. Risiko tertinggi penyakit akibat kerja adalah gangguan pernafasan dan iritasi kulit atau mata pada kegiatan pencampuran dan pengadukan bahan, serta pembersihan sisa material. Sedangkan risiko tertinggi kecelakaan akibat kerja adalah pada kegiatan pengecekan rolling box. Penggunaan metode HIRARC dan aplikasi probability/likelihood of hazard dan severity of hazard cukup baik untuk menilai risiko kecelakaan kerja dan penyakit akibat kerja. Melakukan perbaikan dan perawatan mesin, penetapan zona bahaya, penggunaan alat pelindung diri, serta pengendalian administratif merupakan upaya yang harus dilakukan untuk menghindari risiko akibat kerja

* Corresponding author: Dwi Desianna

Jl. Soekarno-Hatta No 6, Bandar Lampung, Provinsi Lampung

Email : dwidesianna123@gmail.com 


\section{PENDAHULUAN}

Potensi bahaya atau hazards terdapat hampir di seluruh tempat kerja yang dapat mengakibatkan terjadinya kecelakaan yang berdampak kerugian terhadap manusia, peralatan, material, dan lingkungan (Anthony, 2019; Indragiri \& Yuttya, 2020; Kusumawardhani, Kasjono, \& Purwanto, 2017; OHSAS, 2007; Putri \& Trifiananto, 2019; Saputra, 2015; Urrohmah \& Riandadari, 2019; Zeinda \& Hidayat, 2017). Data International Labour Organization (ILO), memperkirakan 2,3 juta pekerja meninggal setiap tahun akibat kecelakaan kerja dan penyakit akibat kerja (PAK). Di Indonesia, angka kecelakaan kerja menunjukkan trend meningkat. Badan Penyelenggara Jaminan Sosial (BPJS) ketenagakerjaan melaporkan, pada tahun 2017 angka kecelakaan kerja sebanyak 123.041 kasus, dan pada tahun 2018 meningkat menjadi 173.105 kasus dengan klaim Jaminan Kecelakaan Kerja (JKK) sebesar Rp. 1,2 triliun (BPJSKetenagakerjaan, 2019).

Besarnya risiko kerja bergantung pada jenis industri, teknologi serta upaya pengendalian risiko yang dilakukan. Kecelakaan akibat kerja adalah kecelakaan yang terjadi dikarenakan oleh pekerjaan atau pada waktu melaksanaan pekerjaan pada perusahaan. Secara garis besar kejadian kecelakaan kerja disebabkan oleh dua faktor, yaitu tindakan manusia yang tidak memenuhi keselamatan kerja (unsafe act) dan keadaan lingkungan yang tidak aman (unsafe condition) (Anthony, 2019; Putri \& Trifiananto, 2019; Urrohmah \& Riandadari, 2019)

Identifikasi bahaya (hazards identification), penilaian risiko (risk assessment) dan pengendalian risiko (risk control)atau HIRARC merupakan elemen pokok dalam sistem manajemen Keselamatan dan Kesehatan Kerja (K3), serta berkaitan dengan upaya pencegahan dan pengendalian bahaya (Anthony, 2019; Indragiri \& Yuttya, 2020; Kusumawardhani et al., 2017; Nalhadi \& Rizaal, 2015; Putri \& Trifiananto, 2019; Supriyadi \& Ramdan, 2017; Urrohmah \& Riandadari, 2019). HIRARC dilakukan pada seluruh aktivitas untuk menentukan kegiatan yang mengandung potensi bahaya dan menimbulkan dampak serius terhadap keselamatan dan kesehatan kerja (Indragiri \& Yuttya, 2020; Kusumawardhani et al., 2017;
Nalhadi \& Rizaal, 2015; Saputra, 2015; Supriyadi \& Ramdan, 2017; Urrohmah \& Riandadari, 2019)

Pada penilaian risiko, Australia menggunakan standarisasi yang dikenal dengan Australian Standard/New Zealand Standard of Risk Management (Standards \& Australia, 1999). Pada standarisasi tersebut terdapat 2 parameter yang dijadikan penilaian risiko yaitu likelihood of hazard dan severity of hazard. Likelihood diberi rentang antara suatu risiko yang jarang terjadi sampai dengan risiko yang terjadi setiap saat (Industry Safe, 2018; Naval Safety Centre, 2018; Society, 2020; Standards \& Australia, 1999; USPAS, 2012).

PT Sinar Laut Indah merupakan perusahaan yang bergerak di bidang konstruksi dengan produk utama genteng beton, paving block, batako dan papan precon. Selama tahun 2019 dilaporkan telah terjadi 2 kecelakaan kerja. Hasil studi pendahuluan mendapatkan bahwa perusahaan belum melakukan perencanaan K3 sebagai dasar menentukan kebijakan K3. Penelitian bertujuan untuk mengetahui bahaya dan penilaian risiko kerja di PT Sinar Laut Indah yang meliputi tahapan hazard identification, risk assessment, dan risk control. Pada tahapan risk assessment, juga digunakan metode likelihood of hazard dan severity of hazard untuk menentukan bobot risiko.

\section{METODE}

Penelitian bersifat desktiptif yang dilaksanakan di PT Sinar Laut Indah Natar Lampung Selatan pada bulan April tahun 2020. Perusahaan menghasilkan beberapa produk bahan konstruksi. Namun, pada pada studi ini hanya melakukan penilaian risiko pada proses produksi paving block sebagai produk unggulan. Pengumpulan data dilakukan dengan cara pengamatan dan pengukuran kualitas lingkungan kerja.

Tahap Hazard Identification dilakukan dengan melakukan pengamatan dan penilaian terhadap seluruh tahapan pekerjaan dan peralatan yang digunakan, serta melakukan pengukuran kualitas lingkungan, meliputi kebisingan, pencahayaan, suhu lingkungan, serta kadar debu.

Tahapan Risk Assessment dilakukan menggunakan metode likelihood of hazard dan severity of hazard. Likelihood of hazard adalah penilaian besarnya probabilitas paparan dari 
faktor risk, dikelompokkan menjadi Almost Certain, Likely, Prosibble, Unlikely, dan Rare. Sedangkan severity of hazard merupakan penilaian konsekwensi dari paparan faktor risiko, dikelompokkan menjadi Insignificant, Mayor, Moderate, Minor, dan Catastropic. Hasil Risk Assessment pada Matrik 1.

Matrik 1. Risk Assessment Matrix Level-Level of Risk

\begin{tabular}{|c|c|c|c|c|c|}
\hline \multirow{2}{*}{$\begin{array}{l}\text { LIKELIHOOD OF } \\
\text { HAZARD }\end{array}$} & \multicolumn{5}{|c|}{ SEVERITY OF HAZARD } \\
\hline & $\begin{array}{l}\text { Insignificant } \\
\text { (1) }\end{array}$ & Minor (2) & Moderate (3) & Major (4) & $\begin{array}{l}\text { Catastrophic } \\
\text { (5) }\end{array}$ \\
\hline A (Almost certain) & Hight & Hight & Extreme & Extreme & Extreme \\
\hline B (Likely) & Moderate & Hight & Hight & Extreme & Extreme \\
\hline C (Moderate) & Low & $M$ & Hight & Extreme & Extreme \\
\hline D (Unlikely) & Low & Low & Moderate & Hight & Extreme \\
\hline $\mathrm{E}$ (Rare) & Low & Low & Moderate & Hight & Hight \\
\hline
\end{tabular}

Tahapan penyusunan Risk Control dilakukan setelah mendapat tingkatan risiko (level of risk), maka disusun upaya pengendalian berdasarkan risiko. Pengendalian risiko merupakan tahapan hirarki yang digunakan dalam pencegahan dan pengendalian risiko yang mungkin terjadi (Tarwaka, 2017). Tahapan pengendalian meliputi eliminasi, substitusi, rekayasa teknik, isolasi, pengendalian administrasi, dan penggunaan APD.

\section{HASIL}

\section{Identifikasi Hazard}

Hasil identifikasi hazard pada bagian produksi paving block menggunakan metode HIRARC mendapatkan beberapa potensi yang termasuk dalam kategori rendah dan tinggi. Penggolongan hazard berdasarkan jenis bahaya keselamatan kerja yaitu bahaya fisik, bahaya kimia, bahaya fisiologis, bahaya mekanik. Sedangkan berdasarkan sumber adalah peralatan, bahan dan cara kerja. Hasil pengukuran faktor lingkungan (Matrik 2), mendapatkan bahwa intensitas kebisingan, pencahayaan dan suhu telah melebihi nilai ambang batas (NAB) berdasarkan Permenaker No. 05 Tahun 2018. Sedangkan kadar debu masih memenuhi persyaratan yang diperkenankan.

Hazard pada cara kerja berkaitan dengan bahan dan peralatan yang digunakan. Potensi risiko pada proses kerja adalah pada kegiatan pengadukan bahan, pengecekan box rolling, pencetakan paving block, membersihkan sisa material, dan penyaringan pasir. Bahaya yang mungkin terjadi adalah cidera ringan hingga berat akibat terjatuh, tertimpa, terjepit, gangguan pernafasan dan iritasi mata.

Matrik 2. Hasil Pengukuran Faktor Lingkungan

\begin{tabular}{lllll}
\hline No. & Pengukuran & Standar & Hasil ukur & Risiko \\
\hline 1. & Kebisingan & $85 \mathrm{dBa}$ & $97 \mathrm{dBa}$ & Gangguan pendengaran \\
2. & Pencahayaan & $50 \mathrm{lux}$ & $188 \mathrm{lux}$ & Silau, gangguan kerja \\
3. & Suhu & $32^{\circ} \mathrm{C}$ & $34^{\circ} \mathrm{C}$ & Dehidrasi, gangguan kerja \\
4. & Debu & $10 \mathrm{mg} / \mathrm{m}^{3}$ & $0,037 \mathrm{mg} / \mathrm{m}^{3}$ & Gangguan pernafasan, iritasi \\
\hline
\end{tabular}

Bahan utama yang digunakan pada proses produksi adalah semen dan pasir. Potensi risiko berdasarkan bahan adalah gangguan pernafasan dan isritasi akibat paparan debu semen dan pasir. Sedangkan potensi risiko dari peralatan adalah gangguan pendengaran akibat bising yang dihasilkan serta cidera ringan hingga berat (Matrik 3).
Matrik 3. Penilaian Hazard

\begin{tabular}{lll}
\hline No. & Pengukuran & Risiko \\
\hline 1. & Bahan & Gangguan pernafasan, iritasi \\
2. & Peralatan & $\begin{array}{l}\text { Gangguan pendengaran, } \\
\text { cidera }\end{array}$ \\
3. & Cara Kerja & Cidera ringan hingga berat \\
\hline
\end{tabular}




\section{Risk Assesment}

Penilaian risiko dilakukan menggunakan metode likelihood of hazard dan severity of hazard. Masing-masing potensi risiko dikelompokkan berdasarkan likelihood of hazard, terdiri dari Almost certain (A), Likely (B), Prosibble (C), Unlikely (D), dan Rare (E). Penilaian severity of hazard terdiri dari Insignificant (1), Mayor (2), Moderate (3), Minor (4), dan Catastropic (5). Sedangkan hasil paduan antara likelihood of hazard dan severity of hazard, dikelompokkan menjadi Risiko sangat tinggi (Ekstrim); Risiko tinggi (Hight); Risiko sedang (Medium); dan Risiko rendah (Low).

Matrik 4. Hasil Penilaian Tingkatan Risiko

\begin{tabular}{llll}
\hline No & Tingkat Risiko & Sumber & Risiko \\
\hline 1 & Tinggi $(\mathrm{H})$ & Debu bahan & Gangguan pernafasan, iritasi kulit/mata \\
& & Mesin berputar & Cidera \\
& & Belt Conveyor & Tertimpa box \\
& & Kebisingan alat & Gangguan pendengaran \\
2 & Sedang (M) & Mencampur dengan & Cidera \\
& & Cangkul dan sekop & \\
3 & Rendah (L) & Naik turun tangga & Cidera \\
& & Lantai basah & Cidera \\
& & Udara panas & Dehidrasi \\
\hline
\end{tabular}

\section{Risk Control}

Penyusunan risk control atau pengendalian risiko dilakukan setelah tahapan penyusunan tingkatan risiko. Penyusunan upaya pengendalian dikelompokkan berdasarkan sumber, kegiatan, dan risiko. Pada tulisan ini, hanya disampaikan pengendalian risiko pada kategori tinggi/Hight (Matrik 5).

Matrik 5. Pengendalian Risiko

\begin{tabular}{llll}
\hline No & Kegiatan & Risiko & Pengendalian \\
\hline 1 & $\begin{array}{l}\text { Pencampuran dan } \\
\text { pengadukan } \\
\text { bahan }\end{array}$ & $\begin{array}{l}\text { Gangguan } \\
\text { pernafasan, } \\
\text { iritasi kulit/mata }\end{array}$ & $\begin{array}{l}\text { Pengaturan waktu kerja; Pemberian alat bantu mekanik; } \\
\text { Penyiraman partikel air; Penghisap debu di ruang kerja; } \\
\text { Pemeriksaan kesehatan; Penggunaan APD, Drainase }\end{array}$ \\
& $\begin{array}{l}\text { Cidera ringan } \\
\text { hingga berat }\end{array}$ & $\begin{array}{l}\text { SOP; Pemberian pengaman mesin; Pembuatan pondasi } \\
\text { mesin dengan cor beton; Training K3; Memasang tanda } \\
\text { bahaya; Melakukan pengawasan; APD }\end{array}$ \\
$\begin{array}{l}\text { Pengecekan box } \\
\text { rolling }\end{array}$ & $\begin{array}{l}\text { Cidera ringan } \\
\text { hingga berat } \\
\text { pencetakan }\end{array}$ & $\begin{array}{l}\text { SOP; Pemberian pengaman mesin; Training K3; Memasang } \\
\text { tanda bahaya; Melakukan pengawasan; APD }\end{array}$ \\
& $\begin{array}{l}\text { Gendengaran, } \\
\text { cidera }\end{array}$ & $\begin{array}{l}\text { Pemberian pengaman mesin; Pemberian absorben suara } \\
\text { pada dinding ruang mesin; Pengaturan waktu kerja; APD }\end{array}$ \\
$\begin{array}{l}\text { Pembersihan } \\
\text { material }\end{array}$ & $\begin{array}{l}\text { Gangguan } \\
\text { pernafasan, } \\
\text { iritasi kulit/mata }\end{array}$ & $\begin{array}{l}\text { Pengaturan waktu kerja; Penyiraman partikel air; Penghisap } \\
\text { debu di ruang kerja; Pemeriksaan kesehatan; Penggunaan } \\
\text { APD, Drainase; Pengawasan. }\end{array}$ \\
\hline
\end{tabular}

\section{PEMBAHASAN}

Risiko keselamatan dan kesehatan kerja telah diidentifikasikan. Terdapat 4 jenis risiko yang dapat terjadi pada bagian produksi paving block, yaitu: a) Bahaya fisika, yaitu kebisingan yang bersumber dari mesin press paving block; $b$ ) Bahaya kimia, yaitu ganggaun pernafasan, iritasi mata/kulit yang bersumber dari bahan yang 
digunakan, yaitu semen dan pasir; c) Bahaya mekanik, yaitu cidera ringan hingga berat; d) Bahaya fisiologis, yaitu terpeleset akibat lantai licin dan ketinggian.

Hasil penilaian risiko, terdapat empat jenis kegiatan yang masuk dalam kategori tinggi (hight) dan berkaitan dengan peralatan, bahan dan cara kerja, yaitu :

\section{a. Pencampuran dan pegadukan bahan}

Pengadukan bahan merupakan proses awal pembuatan paving block menggunakan mesin molen yang bekerja dengan sistim berputar. Apabila tidak hati-hati maka dapat berisiko terjatuh ke dalam mesin karena pengaman mesin terlalu rendah, sehingga mengakibatkan cidera berat. Lantai licin dari penggunaan air untuk proses pencampuran, berisiko menyebabkan terpeleset dan terjatuh sehingga berakibat cidera. Upaya pengendalian yang dapat dilakukan antara lain membuat SOP, pemberian pengaman mesin, pembuatan pondasi mesin dengan cor beton, meningkatkan pengetahuan pkerja melalui training $\mathrm{K} 3$, memasang tanda bahaya, penggunaan APD, sistim drainase untuk menghindari genangan air, serta melakukan pengawasan (Indragiri \& Yuttya, 2020; Zeinda \& Hidayat, 2017).

Proses pencampuran dan pengadukan bahan juga menhasilkan debu, hasil pengukuran debu di ruang kerja sebesar $0,037 \mathrm{mg} / \mathrm{m}^{3}$. Walaupun masih berada di bawah $N A B$, namun apabila paparan terjadi terus-menerus dalam waktu lama, akan menyebabkan penyakit pernafasan, yaitu asbestosis, silicosis, pneumocosis (Anthony, 2019; Putri \& Trifiananto, 2019). Pengendalian yang dapat dilakukan antara lain pengaturan waktu kerja, penyiraman partikel air, penghisap debu di ruang kerja (dust collector), pemeriksaan kesehatan berkala, dan penggunaan APD.

\section{b. Pengecekan rolling box}

Pekerjaan pengecekan rolling box dilakukan dengan cara menaiki dan menuruni tangga yang berada di atas mesin pencetak paving block. Risiko pekerjaan ini adalah tertimpa box rolling, terpeleset, dan terjatuh. Risiko terbesar yang dapat menyebabkan cidera berat bahkan kematian adalah tertimpa box akibat putus tali roll.

Pengendalian yang dapat dilakukan yaitu SOP, pemberian pengaman mesin, meningkatkan pengetahuan melalui training $\mathrm{K} 3$, memasang tanda bahaya, melakukan pengawasan, dan penggunaan APD.

\section{c. Pencetakan paving block}

Proses pencetakan paving block menggunakan mesin press yang saat beroperasi menimbulkan suara bising. Terdapat dua risiko utama pada proses pencetakan paving block, yaitu gagguan pendengaran dan cidera akibat terjepit.

Risiko gangguan pendengaran disebabkan oleh suara bising yang dihasilkan oleh mesin. Hasil pengukuran intensitas kebisingan di ruang kerja sebesar $97 \mathrm{dBA}$, dan jauh melebihi NAB yang diperbolehkan. Berdasarkan Permenaker No. 05 Tahun 2018, NAB paparan kebisingan di tempat kerja sebesar 85 dBA untuk maksimal 8 jam kerja sehari (Permenaker RI No. 5/2017, 2018). Apabila paparan terjadi terus-menerus dalam jangka panjang, maka akan terjadi gangguan pendengaran pada pekerja di bagian produksi (Diniari, Eka Prasetya, Nawawiwetu, \& Tualeka, 2017; Sincihu, Dinata, \& Taurusia, 2019). Beberapa upaya yang dapat dilakukan untuk mencegah risiko gangguan pendengaran antara lain memasang absorben suara pada dinding ruang mesin, pengaturan waktu kerja, dan penggunaan APD.

Risiko cidera juga dapat terjadi akibat terjepit mesin pencetak paving block, pada saat operator melakukan pengawasan. Terjepit mesin press dapat berakibat cidera ringan hingga berat, bahkan berakibat kematian. Upaya yang dapat dilakukan adalah memasang pengaman mesin, membuat batas jarak aman, dan memasang tanda peringatan bahaya (Anthony, 2019; OHSAS, 2007; Putri \& Trifiananto, 2019).

\section{d. Pembersihan sisa bahan/material}

Proses pembersihan dilakukan untuk membuang sisa materil yang menempel pada pesin pengaduk dan mesin pencetak. Pembersihan dilakukan secara manual menggunakan sekop, cetok semen, angin betekanan, dan air bertekanan untuk lantai kerja. Risiko yang dapat terjadi adalah gangguan pernafasan, serta terjepit dan terpelintir yang berakibat pada cidera ringan hingga berat, bahkan menyebabkan kematian. 
Gangguan pernafasan terjadi akibat debu yang dihasilkan akibat penyemprotan angin bertekanan. Partikel debu akan berterbangan dan terhirup oleh pekerja (Anthony, 2019; Putri \& Trifiananto, 2019). Upaya yang dapat dilakukan untuk menghindari risiko gangguan pernafasan antara lain pengaturan waktu kerja, penyiraman partikel air, penghisap debu di ruang kerja, pemeriksaan kesehatan berkala, penggunaan APD, dan sistem drainase menghindari genangan air.

Risiko cidera dapat terjadi akibat hidupnya mesin pada saat proses pembersihan. Untuk mencegahnya, maka perlu pengawasan dan memastikan seluruh aliran listrik pada posisi mati. Pengawasan juga dilakukan pada panel listrik, sehingga tidak dimungkinkan pekerja lain menghidupkan mesin pada saat pembersihan. Upaya lain adalah memasang pemberitahuan pada panel listrik dan mengunci panel listrik saat proses pembersihan.

\section{SIMPULAN}

Penggunaan metode likelihood of hazard dan severity of hazard dapat memberikan hasil yang baik pada penilaian risiko kerja. Hasil penelitian mendapatkan 4 kegiatan dengan kategori risiko tinggi, yaitu pencampuran dan pengadukan bahan, pengecekan rolling box, pencetakan paving block, dan pembersihan sisa material.

Risiko tertinggi penyakit akibat kerja adalah gangguan pernafasan dan iritasi kulit atau mata pada kegiatan pencampuran dan pengadukan bahan, serta pembersihan sisa material. Sedangkan risiko tertinggi kecelakaan akibat kerja adalah pada kegiatan pengecekan rolling box.

\section{UCAPAN TERIMAKASIH}

Ucapan terima kasih disampaikan kepada PT Sinar Laut Indah Natar, Lampung Selatan, Provinsi Lampung atas ijin yang diberikan.

\section{DAFTAR PUSTAKA}

Anthony, M. B. (2019). Analisis Risiko Kerja Pada Area Hot Metal Treatment Plant Divisi Blast Furnace Dengan Metode Hazard Identification And Risk Assessment (HIRA). Jurnal INTECH Teknik Industri Universitas Serang Raya, 5, 3542. https://doi.org/10.30656/intech.v5i1.1461 BPJS-Ketenagakerjaan. (2019). Angka Kecelakaan
Kerja Cenderung Meningkat, BPJS

Ketenagakerjaan Bayar Santunan Rp1,2 Triliun.

Retrieved July 28, 2020, from BPJS

Ketenagakerjaan website:

https://www.bpjsketenagakerjaan.go.id/berita/2 3322/Angka-Kecelakaan-Kerja-Cender

Diniari, H. R., Eka Prasetya, T. A., Nawawiwetu, E. D., \& Tualeka, A. R. (2017). Noise Risk Assessment at Air Separation Plant PT. X Surabaya (Nitrogen, Oxygen, and Argon Plant). Journal Of Vocational Health Studies, 1(2), 70.

https://doi.org/10.20473/jvhs.V1.12.2017.70-74

Indragiri, S., \& Yuttya, T. (2020). Manajemen Risiko K3 Menggunakan Hazard Identification Risk Assessment And Risk Control (HIRARC). Jurnal Kesehatan, 9(1), 1080-1094.

https://doi.org/10.38165/jk.v9i1.77

Industry Safe. (2018). Risk Matrix Calculations Severity, Probability, and Risk Assessment. Retrieved July 28, 2020, from https://www.industrysafe.com/blog/risk-matrixcalculations-severity-probability-and-riskassessment/

Kusumawardhani, D., Kasjono, H. S., \& Purwanto, P. (2017). Analisis Hazard Identification, Risk Assessment, and Risk Control (HIRARC) di Bagian Finishing 2 Industri Serikat Pekerja Aluminium Sorosutan Tahun 2017. Sanitasi: Jurnal Kesehatan Lingkungan, 9(1), 1. https://doi.org/10.29238/sanitasi.v9i1.40 Nalhadi, A., \& Rizaal, A. (2015). Identifikasi Bahaya Dan Penilaian Risiko K3 Pada Tindakan Perawatan \& Perbaikan Menggunakan Metode HIRARC.

Naval Safety Centre. (2018). The process of detecting hazards and assessing associated risks The process of detecting hazards and assessing associated risks Risk Assessment What is Risk Assessment? Retrieved July 28, 2020, from https://www.faa.gov/about/initiatives/maintena nce_hf/library/documents/media/hfacs/4_riskas sessment.pdf

OHSAS. (2007). Sistem manajemen keselamatan dan kesehatan kerja - Persyaratan Occupational health and safety management systemsRequirements Translated by Jack Matatula.

Permenaker RI No. 5/2017. Peraturan Menteri Ketenaga Kerjaan Republik Indonesia No. 5 tahun 2018 tentang Keselamatan dan Kesehatan Kerja Lingkungan Kerja. , 4 Jurnal Pendidikan, Teknologi dan Kejuruan § (2018).

Putri, R. N., \& Trifiananto, M. (2019). Analisa Hazard Identification Risk Assessment And Risk Control 
(HIRARC) Pada Perguruan Tinggi Yang Berlokasi Di Pabrik. Seminar Dan Konferensi Nasional IDEC 2019, B11.1-B11.10. Surakarta.

Saputra, A. D. (2015). Gambaran Potensi Bahaya dan Penilaian Risiko Keselamatan dan Kesehatan Kerja Di Bagian Spinning IV Production PT. Asia. Pacific Fibers, TBK. Kabupaten Kendal. 1-114.

Sincihu, Y., Dinata, M., \& Taurusia, M. (2019). Investigation of Noise Induced Hearing Loss at Shipyard Company, Surabaya Investigasi Gangguan Pendengaran akibat Bising di Perusahaan Galangan Kapal, Surabaya. The Indonesian Journal of Occupational Safety and Health, 8, 325-331. https://doi.org/10.20473/ijosh.v8i3.2019.325331

Society, A. C. (2020). Risk Rating \& Assessment American Chemical Society. Retrieved July 28, 2020, from

https://www.acs.org/content/acs/en/chemicalsafety/hazard-assessment/fundamentals/riskassessment.html website:

https://www.acs.org/content/acs/en/chemicalsafety/hazard-assessment/fundamentals/riskassessment.html

Standards, C. of, \& Australia. (1999). Risk
Management AS/NZS 4360:1999 (2nd ed.).

Retrieved from

http://www.epsonet.eu/mediapool/72/723588/d

ata/2017/AS_NZS_4360-

1999_Risk_management.pdf

Supriyadi, S., \& Ramdan, F. (2017). Hazard Identification And Risk Assessment In Boiler Division Using Hazard Identification Risk Assessment And Risk Control (HIRARC). Journal of Industrial Hygiene and Occupational Health, 1(2), 161. https://doi.org/10.21111/jihoh.v1i2.892

Urrohmah, D. S., \& Riandadari, D. (2019). Identifikasi Bahaya Dengan Metode Hazard Identification, Risk Assessment and Risk Control (Hirarc) Dalam Upaya Memperkecil Risiko Kecelakaan Kerja Di Pt. Pal Indonesia. Jurnal Pendidikan Teknik Mesin, 8(1), 34-40.

USPAS. (2012). Controlling Risks Risk Assessment. Zeinda, E. M., \& Hidayat, S. (2017). Risk Assessment Kecelakaan Kerja Pada Pengoperasian Boiler Di PT. Indonesia Power Unit Pembangkitan Semarang. The Indonesian Journal of Occupational Safety and Health, 5(2), 183. https://doi.org/10.20473/ijosh.v5i2.2016.183191 